\title{
A Virtual Factory for Smart City Service Integration
}

\author{
Guillermina Cledou \\ HASLab INESC TEC \\ Universidade do Minho \\ Portugal \\ guillermina.cledou@inescporto.pt
}

\begin{abstract}
In the last years, new technologies - referred as emerging information and communication technologies (EICTs), have appeared and are immersed in peoples' lives assisting them and facilitating their daily activities. Taking advantage of the diffusion and infusion of these technologies, governments are using EICTs to deliver better public services to citizens. However, to address citizens' demands and to provide customer oriented services governments face various types of challenges. The aim of this research work is to provide solutions to some of the challenges, in particular to the rapid development of electronic public services (EPS) and the service integration in the context of development of smart cities. Following the aim, we propose an approach, called Virtual Factory for Smart City Service Integration. The idea of the virtual factory is to provide a framework to automatically produce software based on a given set of specifications of a family of EPS taking advantage of similarities in the EPS business processes. The expected contributions of this research work is to produce a domain specific language (DSL) for service specification and supporting tools that based on the produced specifications, workflow techniques and ideas of software product lines (SPL) can automatically produce software applications for EPS that can be easily parameterized and completed.
\end{abstract}

\section{Categories and Subject Descriptors}

D.2.1 [Requirements/Specifications]: Languages; D.2.4 [Software/Program Verification]: Formal Methods, Model Checking, Validation.

\section{General Terms}

Algorithms, Design, Human Factors, Languages, Reliability, Security, Standardization, Verification

\section{Keywords}

Service Integration; Smart Cities; e-Government; Domain Specific Language; Software Product Line; Workflows; Formal Methods

\section{INTRODUCTION}

In the last years, new technologies have appeared and are immersed in our daily environment contributing to automate and facilitate our activities. Referred as Emerging Information and Communication Technologies (EICTs), they cover a broad spectrum - from software and hardware capabilities replacing or assisting functions of the human body, like cyborg technology; to

Permission to make digital or hard copies of all or part of this work for personal or classroom use is granted without fee provided that copies are not made or distributed for profit or commercial advantage and that copies bear this notice and the full citation on the first page. Copyrights for components of this work owned by others than ACM must be honored. Abstracting with credit is permitted. To copy otherwise, or republish, to post on servers or to redistribute to lists, requires prior specific permission and/or a fee. Request permissions from Permissions@acm.org.

ICEGOV2014, October 27 - 30 2014, Guimaraes, Portugal Copyright 2014 ACM 978-1-60558-611-3/14/10 ..\$15.00 http://dx.doi.org/10.1145/2691195.2691288 the innovative use of existent technologies to enhance public services, such as closed circuit television and facial and pattern recognition used for vehicle and citizen recognition in controlling city transport and in enhancing security measures [1].

Due to the embeddedness of EICTs, citizens are more and more used to interact with them on a daily bases, putting pressure on governments for them to take advantage of such technologies to provide better EPS. Citizens can benefit from the use of EICTs, particularly in three main areas: 1) improvements in the way they receive services; 2) improvements in the interactions with government; and 3) improvements in their quality of lives. The use of EICTs to provide EPS also benefits governments: 1) providing tools to facilitate information sharing among government agencies; 2) increasing effectiveness and efficiency [14]; 3) promoting sound economic growth [4]; and 4) providing tools to deliver public value.

In the context of smart cities and taking advantage of the diffusion and infusion of the EICTs, governments are developing EPS and pursuing the aforementioned benefits [9]. However efficient and effective delivery of EPS encompasses many technical and organizational challenges. Examples of technical challenges include: t1) rapid development of EPS [13]; t2) service integration [7]; t3) multichannel delivery of EPS [5]; t4) concerns about privacy and security [21]; t5) usability of EPS [6]. Examples of organizational challenges include: o1) business process integration; o2) matching citizens needs [6]; o3) costs [17]; and o4) correspondence between traditional and electronic services [21].

The remaining of this document is structured as follows. Section 2 discusses the problem domain. Section 3 presents some related work. Section 4 presents the research problem and the research questions. Section 5 presents the methodology proposed to address the research questions. Section 6 discusses the identification of a possible family of EPS to serve as case study. Section 7 presents the expected contributions. Finally, Section 8 draws some conclusions.

\section{PROBLEM DOMAIN}

An EPS is a service delivered in benefit of the public using ICT to facilitate the delivery of the service and to support the interaction between the providers and the consumers [7]. Depending on the different aspects of an EPS, there are various ways of classifying them, such as: 1) type of process - classifies public services based on the kind of the underlying business process. The categories include: routine, individualized case processing, negotiation and others [21]; 2) type of the service - classifies services based on the type of service provided by public authorities. The categories include: certification, authorization, control, and production [20]; 3) service recipients - classifies services depending on their recipients. The categories include: G2C (services to citizens), G2B (to businesses), G2G (to government), G2E (to employees), and G2V (to visitors), among othersl and 4) government area - 
classifies services based on the public entity acting as service provider. Some categories include: health, education, justice, etc.

For the purpose of this study we are mostly interested in the latter classification since we would like to identify a family of services that share similar functionality, and therefore, can be produced through the concept of "a virtual factory". Based on the case studies analyzed during the literature review, we identify nine government areas from which we can select a family of EPS: 1) transport, 2) health, 3) environment, 4) security, 5) education, 6) economy, 7) social welfare, 8) tourism, and 9) labor.

\section{RELATED WORK}

To address the challenges of service integration several approaches have been proposed in the literature - frameworks for development of EPS, interoperability frameworks, enterprise architectures, ontologies, etc. For example, [13] proposes a software infrastructure for rapid cross-agency development of EPS. By using a generic business and software process it enables: government customers to submit applications and track their current status; and government agencies to process such applications and collaborate with each other by exchanging information, among other functionalities. In [3] the authors studied the use of Enterprise Portals to overcome the lack of horizontal and vertical integration of business processes of government agencies for delivering public services.

In the area of EPS for smart cities there are many initiatives undertaken by governments all over the world. Following the selected classification of EPS, and highlighting those categories of more interest for local governments, some examples of EPS for smart cities include: in Transport - automatic payment of road tolls and parking fees through the use of Radio Frequencies Identification (RFID) devices [19]; in Health - preventive medicine through DNA screening [1]; in Environment - smart monitoring and control of water and energy consumption in public buildings and houses through the use of a network of smart sensors and meters [12]; in Security - faster and more robust identification of individuals through the use of biometrics [1]; and in Education - online access to scholar data of public schools through the use of broadband networks [16].

In the area of DSL applied to the e-Government domain, only five publications were found from a search in Scopus database using the keywords "Domain Specific Language" and "Government". In particular, [10] proposes a DSL for procedure management in eGovernment. [18] discusses the use of a DSL for business modeling of administrative processes to facilitate compliance with the legislations that regulate government procedures. [11] proposes a DSL for web service composition. [15] applies DSLs to aid in the development of a system to teach students about radiological, chemical and biological weapons using $3 \mathrm{D}$ simulations. [8] presents a kind of DSL that provides a semantic model to specify process-driven exchange of messages between applications, enabling high-level messaging services through dynamically enabled horizontal (process independent) and vertical (process dependent) extensions.

The use of SPL in government applications is described in [2]. It proposes a framework for creating Geographic Information Systems (GIS) using a SPL with the intention of facilitating the provision of GIS- related services from governments to citizens.

\section{RESEARCH PROBLEM}

To address some of the challenges explained in the introduction i.e. $\mathrm{t} 1, \mathrm{t} 2$, o1 and to some extent $\mathrm{o} 2$, and $\mathrm{o} 3$; the aim of this research work is to propose a new approach, called Virtual Factory for Smart City Service Integration, for the development and integration of city-level EPS and to validate the proposed approach through real-life case studies. From the informatics point of view, the goal is to advance the state of the art in software modeling and development tools for the rapid development of integrated EPS delivered by local governments in the context of smart city initiatives.

To fulfill the goal, the PhD thesis will address the following research questions:

1. How to develop models for capturing common functionality included in business processes of a family of EPS delivered by local governments in the context of smart cities?

2. Based on the generated models, how to provide a domainspecific framework, including software tools that can automatically generate software for the identified family of EPS?

As mentioned in Section 1, main technical and organizational challenges face by governments to deliver EPS relate to the rapid provision of public services in an integrated and seamless way, addressing the real needs of citizens. Following literature review briefly presented in Section 3, we observe various types of initiatives that were undertaken to solve this problem by integrating the very diverse systems existing in government agencies. While mostly the adopted approaches take advantages of existing tools, the idea of a Virtual Factory presented here suggests tackling the problem from a different perspective. This means: 1) to develop a domain-specific language to capture syntactically and semantically the functionality, in particular common functionality, of public services delivered in the context of smart city development; 2) to use workflow techniques to orchestrate the combination of reusable functionality specified through the proposed language to generate software applications for delivering EPS; and 3) to combine 1),2) and the concept of Software Product Line (SPL) using Software Engineering (SE) techniques in a framework able to produce software from the specifications of public services. The envisioned framework will serve as a "virtual factory" enabling the easy and rapid development of a family of EPS. The "virtual factory" will take as inputs the specifications of new services in the defined DSL, and will produce as outputs the corresponding software applications, or at least a significant part of them that can be easily parameterized and completed.

It is expected that the proposed approach will be validated by illustrating how software applications for selected EPS of an identified family can be generated, showing improvements between traditional development approaches and the Virtual Factory approach, as well as in the tools used for specifying, integrating and generating domain-specific applications.

\section{METHODOLOGY}

In order to address the research questions introduced in Section 4, we proposed a research methodology comprising the activities described below. The methodology is illustrated in Figure .

A1. Smart City EPS - State-of-Art: assessment of existing approaches to develop and integrate city-level EPS.

A2. Family of EPS - Selection: identification of a broad family of city-level EPS with high value for city inhabitants and amendable to be delivered through business processes sharing common vocabulary and functionality. 
A3. Computational Tools for Service Development and Integration (SDI) - State-of-Art: analyzing existing approaches, tools and techniques to specify, develop and verify models of business processes of EPS including DSLs, workflows, and SPLs.

A4. DSL Definition: development of DSL addressing specificities of EPS, able to capture uniformly the common vocabulary, functionality and properties, both in terms of syntax and operational semantics.

A5. Model Construction: building models for the identified family of EPS to capture uniform delivery of all services in the family by executing the corresponding business processes and using the DSL designed in A4.

A6. Virtual Factory Definition: integration of the DSL, workflow techniques and the concept of SPL to provide a framework that will serve as a virtual factory for the creation of EPS (see Figure 2).

A7. Software Prototype: building a software prototype platform to showcase the feasibility of the virtual factory. The prototype is expected to include a visual interface to facilitate its usage by domain (non-technical) experts.

A8. Guidelines: defining a set of technical guidelines to support the creation of software applications for EPS using the virtual factory, in particular the DSL defined in A4 and the use of the prototype built in A6.

A9. Validation: validating the approach through a real-life citylevel public service case study belonging to the family selected in A2 based on the model constructed in A5.

A10.Dissemination: sharing the research findings of the thesis through conference and journal publications, as well as lecture presentations, whenever possible.

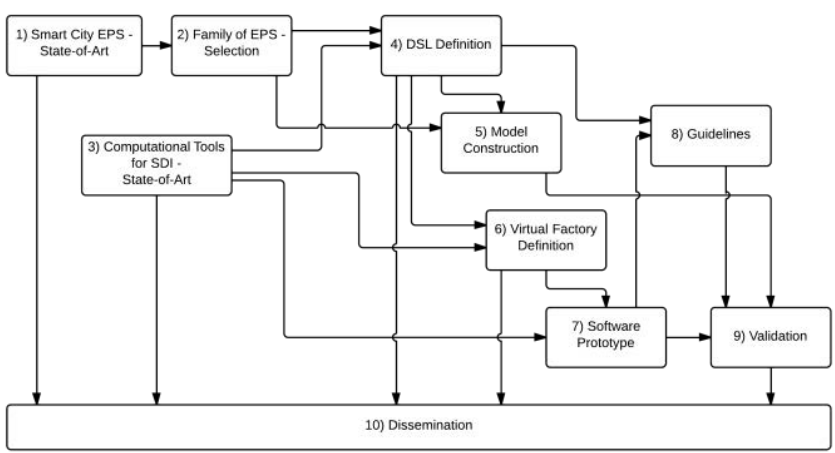

Figure 1: Research methodology

A Virtual Factory for Smart City Service Integration

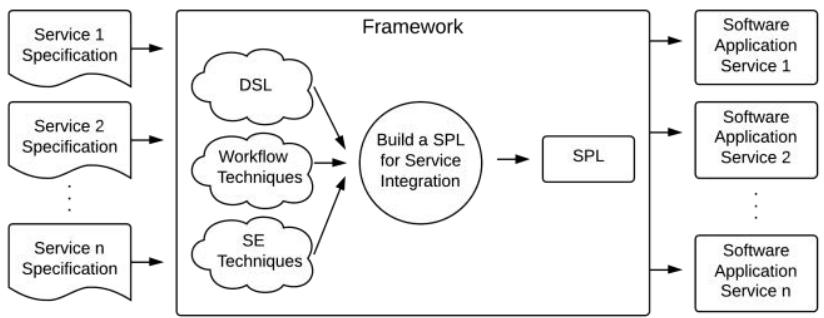

Figure 2: Virtual factory framework for service integration

\section{IDENTIFYING A CASE STUDY}

To determine a family of EPS, this section takes as starting point the government area of Transport. Since EPS are developed in the benefit of the public, it is beneficial to think from the user point of view when trying to develop new services. Such approach can increase the chances of having a higher level of acceptance and success when the new service is made available. This user's perspective approach is applied to classify some examples of EPS related to transport according to the service beneficiary, which helped to understand better the functionality provided by the services leading to the proposition of some selected services.

The selected group of EPS by beneficiary includes: B1) for Public Transport - S1) finding the location of a public bus, S2) finding the location of a train, S3) finding the location of the nearest taxi stop, and S4) getting faster green lights for public transport; Drivers (Motor-vehicle) - S5) automatic payment of road fees, S6) automatic payment of parking places, S7) easy payment of street parking places, S8) finding the nearest electric vehicle charging station, S9) finding the nearest parking place, and S10) guided transportation for emergency vehicles; Drivers (Bicycles) - S11) getting faster green lights for cyclists, S12) finding the location of public bicycles sharing systems, and S13) easy payment of bicycle sharing systems; B2) for Transport Authorities - S14) localization of stolen vehicles, S15) automatic detection of illegal behavior, and S16) automatic detection of avoidance of obligations; and B3) for the Public - S17) information about garbage collection, and S18) information about snow removal.

To identify the common functionalities of the identified services we studied the business processes and discovered the following common functionality: F1) showing the position of an object in the map, F2) calculating the distance between two objects, F3) displaying the (best) route between two objects, F4) calculating the estimated meeting time of two (possible moving) objects, F5) recognizing the occurrence of an event in a particular place, F6) booking a resource, and F7) issuing a payment. Erro! A origem da referência não foi encontrada. shows the EPS highlighting the basic functionality they provide.

The identified common functionality hints some likely commonality in the services business processes. Thus, such shared processes could be treated as independent modules (a kind of pattern) for easier development of services in a given EPS family. The shared functionality by services is shown in Table 1 .

\section{EXPECTED CONTRIBUTIONS}

Expected contributions include: 1) a comprehensive survey on the state of the art of EPS for smart cities; 2) a comprehensive survey on the state of the art on computational tools for service development and integration, particularly in the EPS domain; 3) a DSL for the specification of EPS; 4) the validation of the DSL through models constructed for a selected family of EPS; 5) a software prototype to implement and validate the approach; and 6) the validated virtual factory framework.

Table 1. Basic functionalities for a group of EPS.

\begin{tabular}{|c|c|c|c|c|c|c|c|c|c|c|c|c|c|c|c|c|c|c|}
\hline & S1 & S2 & S3 & S4 & S5 & S6 & S7 & S8 & S9 & S10 & S11 & S12 & S13 & S14 & S15 & S16 & S17 & S18 \\
\hline F1 & X & X & X & & & & & X & X & X & & X & & X & & & X & X \\
\hline F2 & X & X & X & & & & & X & X & X & & X & & & & & & \\
\hline F3 & X & X & X & & & & X & X & X & & X & & X & & & X & X \\
\hline F4 & X & X & & & & & & & & X & & & & & & & X & X \\
\hline
\end{tabular}




\begin{tabular}{|l|l|l|l|l|l|l|l|l|l|l|l|l|l|l|l|l|l|}
\hline F5 & & & $\mathrm{X}$ & $\mathrm{X}$ & $\mathrm{X}$ & $\mathrm{X}$ & & & & $\mathrm{X}$ & & $\mathrm{X}$ & $\mathrm{X}$ & $\mathrm{X}$ & $\mathrm{X}$ & & \\
\hline F6 & $\mathrm{X}$ & & & & & & $\mathrm{X}$ & & & & & & & & & \\
\hline F7 & $\mathrm{X}$ & & & $\mathrm{X}$ & $\mathrm{X}$ & $\mathrm{X}$ & & $\mathrm{X}$ & & & & $\mathrm{X}$ & & & & & \\
\hline
\end{tabular}

\section{CONCLUSIONS}

The research conducted up to date contributed to support the motivation of the research problem and the need for innovative tools to support EPS development and integration presented in Section 1. The most significant contributions of this research work are expected to be achieved through tasks A4 - DSL Definition, and A6 - Virtual Factory Definition. The findings of these tasks will be validated through tasks: 1) A5-Model Construction - by validating that the defined DSL can effectively model the services of the selected EPS family, 2) A7 - Software Prototype - by implementing the idea of the virtual factory through the prototype, and 3) A9 - Validation - by producing executable code for a selected EPS based on the model specified using the proposed DSL and the virtual factory implemented by the software prototype.

\section{REFERENCES}

[1] Bannister, F. and Wilson, D. 2011. O ( ver ) -Government?: Emerging technology, citizen autonomy and the regulatory state. 16, (2011), 63-79.

[2] Buccella, A. and Cechich, A. 2010. Geographic e-Services Development through Product-Line Engineering and Standardization. Electronic Government and the Information Systems Perspective. K. Andersen et al., eds. Springer Berlin Heidelberg. 150-157.

[3] Daniel, E. and Ward, J. 2006. Integrated service delivery: exploratory case studies of enterprise portal adoption in UK local government. Business Process Management Journal. 12, 1 (2006), 113-123.

[4] Daniel, S. and Marie-Andree, D. 2013. geoSmartCity: geomatics contribution to the Smart City. The Proceedings of the 14th Annual International Conference on Digital Government Research (2013), 65-71.

[5] Deursen, A. Van 2007. Where to Go in the Near Future: Diverging Perspectives on Online Public Service Delivery. Electronic Government. Springer Berlin Heidelberg. 143154.

[6] Deursen, A. Van et al. 2006. Why E-government Usage Lags Behind: Explaining the Gap between Potential and Actual Usage of Electronic Public Services in the Netherlands. Electronic Government. Springer Berlin Heidelberg. 269-280.

[7] Estevez, E. 2014. EGOV Infrastructure and Services, Executive Training for Government Information Officers, Module 5.

[8] Estevez, E. and Janowski, T. 2007. Programmable messaging for electronic government-building a foundation.
Formal methods and hybrid real-time systems. Springer. 217-236.

[9] Harrison, C. et al. 2010. Foundations for Smarter Cities. IBM Journal of Research and Development. 54, 4 (Jul. 2010), 1-16.

[10] Hernández, G.I. et al. 2012. Modelado específico de procedimientos en el dominio de la Administración Electrónica. RISTI-Revista Ibérica de Sistemas e Tecnologias de Informação. 9 (2012), 1-14.

[11] Hu, H. and Yan, G. 2010. Research on DSL-based composition language in service-oriented architecture. Computer Application and System Modeling (ICCASM), 2010 International Conference on (2010), V14-357.

[12] IBM 2012. IBM Smarter Cities.

[13] Janowski, T. et al. 2007. Rapid Development of Electronic Public Services - Software Infrastructure and Software Process. 8th Annual International Digital Government Research Conference (2007), 294-295.

[14] Jung, M. et al. 2013. Building Automation and Smart Cities: An Integration Approach Based on a Service-Oriented Architecture. 27th International Conference on Advanced Information Networking and Applications Workshops. (Mar. 2013), 1361-1367.

[15] Kidd, E. 2007. Terrorism response training in scheme. Proceedings of the 4th ACM SIGPLAN workshop on Commercial users of functional programming (2007), 6 .

[16] Macadar, M.A. and Lheureux-De-Freitas, J. 2013. Porto Alegre: a Brazilian city searching to be smarter. Proceedings of the 14th Annual International Conference on Digital Government Research (2013), 56-64.

[17] Nam, T. and Pardo, T. a. 2011. Conceptualizing Smart City with Dimensions of Technology, People, and Institutions. Proceedings of the 12th Annual International Digital Government Research Conference on Digital Government Innovation in Challenging Times - dg.o ' 11 (New York, New York, USA, 2011), 282.

[18] Nešković, S. et al. 2011. Using protocols and domain specific languages to achieve compliance of administrative processes with legislation. Electronic Government and the Information Systems Perspective. Springer. 284-298.

[19] Oja, M. 2008. Electronic Government in the Age of Ubiquitous Computing. University of Lübeck.

[20] Peristeras, V. and Tarabanis, K. 2004. Governance Enterprise Architecture (GEA): Domain Models for eGovernance. ICEC'04, Sixth International Conference on Electronic Commerce (2004), 471-479.

[21] Wimmer, M. a. 2002. A European perspective towards online one-stop government: the eGOV project. Electronic Commerce Research and Applications. 1, 1 (Mar. 2002), 92103. 